\title{
The impact of social media on customers' image for mobiles
}

\author{
TAREQ NAEL HASHEM *
}

Al-Isra University, Amman, Jordan

\author{
Key Words \\ Social media \\ Customers \\ Image \\ Amman
}

Received: 22 July 2016

Accepted: 15 August 2016

Published: 27 October 2016

\begin{abstract}
This study aims to investigate the impact of social media on customers' image of mobiles. The study population consists of mobile customers who are using social media in Amman. A convenience sample consisting of 500 customers was selected from the targeted population. Five hundred questionnaires were distributed over the study sample; 404 questionnaires were collected, which represent $80.8 \%$ of the total sample. The study results indicated that social media has an impact on customers' image of mobiles. The study also found no statistical difference in social media impact on customers' image for mobiles due to gender, and there is no statistical difference in social media impact on customers' image for mobiles due to age. Moreover, there is no statistical difference in the impact of social media on customers' image for mobiles due to income.
\end{abstract}

(C2016 TAF Publishing. All rights reserved.

\section{INTRODUCTION}

The ongoing development and enhancement in the technical field have led the world to be automated somehow. Nowadays, most of the human activities are held and accomplished through technology mainly through the World Wide Web. Many of these activities are seen to be essential and have to be completed on time, so, people have seen technology as a fast way to get their duties done as per their wishes and in minimum time required (Thiebaud, 2010; Kincaid, 2004).

Among the most noticeable and widely spread invention of technology is the notion of the social networking or-aka-social media. With the emergence of social media, there appeared the concept of E-Marketing; the Electronic marketing or the so called e-marketing that is defined as a new philosophy of marketing and promoting the goods, products, services and materials through the world wide web without the need of roaming from one place to another and with the comfort of one's own home/office (Al-Gohary, 2010). According to Al-Gohary (2010) the idea of e-marketing was the idea of the small business organization which can't afford the expenses of real life marketing or doesn't have the assists to run marketing campaigns. Generally speaking, social media or social networking sites are considered to be one of the most important marketing tools that have the ability to present the same results as that of real life marketing chain. What is seen to be helpful in such tools is the wide accessibility that customers have in terms of checking the product, its specifications, checking the reviews on the product or the service or even spreading the word from one place to another. It can be noticed that marketing through social media

\footnotetext{
${ }^{*}$ Corresponding author: Tareq Nael Hashem

†Email: tareqhashem1975@yahoo.com
} 
has spread widely during the first decade of the third millennium and managed to attract the attention of millions of users worldwide (Furrer and Devanathan, 2001).

From another perspective, Kaplan and Michael (2010) pointed to social media as a group of internet based applications that forms the technical foundations of the known web 2.0 in a way that opens the gates of the interaction and exchanging between individuals regardless of their geographical existence.

However, Kaplan and Michael (2010) stated that there are many types of social media and it doesn't come only in one form. These aspects are: a) social networks b) blogs c) Wikis d) podcasts e) forums f) content communities and g) micro-blogging. While the social media and social networking are seen to be a vital tool in the field of human interaction in a way that it helps in deepening the means of the familial connections and social bonding. From the field of media, the social networking gives the interaction and transaction between all parties through emailing, sharing and inviting (Russell, 2007).

From the e-marketing tools and social media marketing campaigns that are taking place is the mobile marketing. This concept is widely used nowadays due to its easiness, availability and affordability. Mobile marketing was defined by Shankar and Sridhar (2009, 118) as " The two- or multi-way communication and promotion of an offer between a firm and its customers using a mobile medium, device, or technology".

tab Vitak et al. (2011) sees that e-marketing forms a good tool that gives organizations and establishments the ability to reach the maximum number of customers who are willing to buy and try based on their own experiences, interests and hobbies. In that sense, Pradiptarini (2011) confirms that the e-marketing which is done either through emails or through social media sites are helpful in increasing the involvement of the company in other markets specifically competitors' markets and other marketing platforms. In addition to that, it helps in the political field social media that is now the main and only tool where people can comment and argue about their political views and find their supporters on those views.

In general, in the field of e-marketing, social media or social networking sites are now used for the sake of marketing and promoting products, services and goods in order to reach the communities of potential customers who may form a future purchaser of the products through focusing on the product itself, seeing the reviews that are related to it, connecting with people who had experience in using the product and observing the tendencies of the product's success (Owen and Humphrey, 2009).

\section{Image}

Nguyen (2006) argues that usually, when people, tourists, travelers or individuals hear about a certain place, or a destination, they immediately connect it to the corporate image. While Schiffman and Kanuk $(1997,171)$ sees that "Customers tend to deal with organizations that have images consistent with their own self-images". In general, corporate image refers to the way people-customers-receive the company or its products (Kotler and Kevin, 2006). From another point of view, Bouchet (2004) sees that the corporate image/identity "are concepts occupying the minds of companies and organizations of our time, because things must be connected in a world where every institution's or person's role and place are renegotiated almost every day". However, Bouchet (2004) argues that the modern life style nowadays is seen as more important compared to the old lifestyle that people used to lead. For example, it is not what to eat and how to eat that matters to us, it is where and what brand we are eating. It is worth to note that corporate image is based on two principles, the functional and the emotional (Kennedy, 1977). The func- 
tional aspect refers to the aspects that can be easily measured while the emotional aspect is bound to the psychological, emotional and self attitudes that are highlighted through the customers towards a firm/brand (Nguyen and Gaston, 2001). In general, the corporate image is the impression that an organization leaves in its customers' mind, it revolves around the ideas, emotions, feelings, attitudes and tendencies that appear when the corporation is mentioned or when it introduces a new product. Mainly, the image can be perceived when the customers have interaction with the corporate identity, the brand itself, the service that the corporate presents, and the nature of the marketing campaigns that a corporation is leading (Cornelissen, 2000).

According to Kehinde et al. (2015), corporations are now losing their loyal customers and the level of their branding, it can be attributed to the lack of the social connections that a corporation has to develop with its loyal communities which may lead them to losing the importance of their products and open the gate to other competitors to take the lead. In that sense, social media might be of help in preserving the image of the brand in its highest levels through the interconnections and the constant bonding with the customers through social networking sites.

\section{Study Problem}

Recently, and with the corporate undeniable interest in promoting their goods and services via social media tools, it has been noticed that Social media's impact on customers' image for mobiles is considered to be an important topic to examine This stems from the customers' deep interaction with social media websites in all its forms and for many different reasons including fun, meeting new people and shopping. This widespread interaction can be somehow attributed to the nature and tendencies of social media websites which manage to create an impact on the customers' preferences and perceptions (Diga and Tom, 2002). The study problem can be addressed by answering the following questions:

1. Is there an impact of social media on customers'image for mobiles?

2. Is there any statistical difference in the impact of social media on customers'image of mobiles due to: a) gender; b) age; c) income?

\section{Study Importance}

The study's importance stems from the role played by social media in the marketing field in general, in its impact on customers' image for mobiles in particular. Not to mention the different approaches that are used by the mobile companies in order to increase the effectiveness of positioning strategies for their products and increase the number of their potential customers as a database that will form a strong tool for the company in the future to promote, market and spread their new products and services.

\section{Study objectives}

The study aims to reveal the "impact of social media on the customer's image for mobiles"; this aim will be achieved through actualizing the following set of objectives:

1. To investigate the impact of social media on the customer's image for mobiles

2. To investigate if there is any statistical difference in the impact of social media on the customer's image for mobiles due to: a) gender; b) age; c) income.

\section{Study Hypotheses}

H01: There is no impact of social media on the customers' image for mobiles.

H02: There is no statistical difference in the impact of social media on the customers' image for mobiles due to gender.

H03: There is no statistical difference in the impact of social media on the customers' 
image for mobiles due to age.

H04: There is no statistical difference in the impact of social media on the customers' image for mobiles due to income.

\section{METHODOLOGY}

In actualizing the objectives of the study and hence reaching the previously set aim, the researcher will apply a quantitative approach which can be employed to describe a certain phenomenon based on describing the tendencies of the varied relationships in accordance with a set of measurable, observable data and variables. The current research study is descriptive and analytical in its scientific existence. A questionnaire will be used as a tool for the research which consists of two sections; the first section will bear the demographic variables of the sample of the study while the second section will address variables of the study based on the main topic in order to serve the study objectives.

\section{Data Collection Methods}

1-Primary source: the study questionnaire that was designed and distributed to the participants of the study, which will be extracted from the research population.

2-Secondary sources: books, references, previous studies on that handle study topic.

Population and Sampling

The study population includes mobile customers who use social media and live in Amman. The study convenience sample consisted of 500 customers. 404 questionnaires were retrieved presenting $80.8 \%$ of the sample as a whole.

\section{Reliability Test}

A Cronbach Alpha test was used to ensure the instrument's reliability. The value was $81.5 \%$ for the questionnaire. All values are accepted since they are more than $60 \%$ (18).

\section{Statistical treatment Methods}

The "SPSS" statistical package program was used in order to analyze the collected data through the questionnaire. The following statistical methods were used:

- Frequencies and percentages

- Means and standard deviations

- Simple Regression tests

- 2-way ANOVA

\section{ANALYSIS AND DISCUSSION}

Frequency and percentages were computed for the sample's characteristics. The table 1 indicates that $7.2 \%$ of the sample have a diploma or less, $83.7 \%$ of the sample have bachelor degree, and the rest have higher studies. The above table also shows that there are more males than females. There are 296 males, with $73.3 \%$ of the total share. There are 108 females, with $26.7 \%$ of the total share. With respect to income, the table shows that $38.9 \%$ of the sample earns less than $\$ 500$ per month, whereas $28.2 \%$ of the sample earns between $\$ 100$ and $\$ 1500$ per month. Finally, it is found that the majority of the sample $(78 \%)$ is between 20 and 30 years old.

Table 2 indicates that the means of the sample's responses to questions 2, 4, 8 and 11 are less than the virtual mean (3), which means that there are negative attitudes towards these questions. On the other hand, there are positive attitudes towards the rest of the questions because their means are above the mean of the scale (3). The grand mean also reflects that there are positive attitudes towards all the questions. 
TABLE 1. Sample's distribution according to demographic information

\begin{tabular}{lll}
\hline \hline Category & Frequency & Percentage\% \\
\hline Education & \\
\hline High School or less & 25 & 6.2 \\
\hline Diploma & 4 & 1.0 \\
\hline Bachelor & 338 & 83.7 \\
\hline Master & 21 & 5.2 \\
\hline PHD & 16 & 4.0 \\
\hline Total & $\mathbf{4 0 4}$ & $\mathbf{1 0 0} \%$ \\
\hline Male & Gender & \\
\hline Female & 296 & 73.3 \\
\hline Total & 108 & 26.7 \\
\hline & $\mathbf{4 0 4}$ & $\mathbf{1 0 0} \%$ \\
\hline Less than $\$ 500$ & Income & \\
\hline \$501-1000 & 157 & 38.9 \\
\hline \$1001-1500 & 109 & 27.0 \\
\hline Above $\$ 1500$ & 24 & 28.2 \\
\hline Total & $\mathbf{4 0 4}$ & 5.9 \\
\hline & $\mathbf{1 0 0} \%$ \\
\hline Less than 20 years & 70 & \\
\hline $20-30$ years & 290 & 71.8 \\
\hline $31-40$ years & 28 & 6.9 \\
\hline $41-50$ years & 10 & 2.5 \\
\hline More than 50 years & 6 & 1.5 \\
\hline Total & $\mathbf{4 0 4}$ & $\mathbf{1 0 0} \%$ \\
\hline \hline
\end{tabular}

TABLE 2 . Means and standard deviations for sample's responses towards social media

\begin{tabular}{lll}
\hline \hline Statement & $\mathbf{x}$ & S.D \\
\hline 1. Attracts my attention to the advertised product & 3.4876 & .90619 \\
\hline 2. Motivates me to buy the advertised products & 2.9926 & .94117 \\
\hline 3. Confines the consumer with the product quality & 3.0223 & .89220 \\
\hline 4. High reliability & 2.6411 & .88123 \\
\hline 5. Eye-catching colors and designs. & 3.7104 & .89264 \\
\hline 6. Clear to the consumer & 3.3812 & 1.04644 \\
\hline 7. Entertaining & 3.4505 & .94253 \\
\hline 8. Not easy to understand & 2.7748 & .86352 \\
\hline 9. Repeated in a boring way & 3.2228 & 1.04484 \\
\hline 10. Gives a positive effect on the advertised brand & 3.3663 & .90735 \\
\hline 11. Motivates me to buy & 2.7822 & .86686 \\
\hline 12. Contributes in accepting the advertised product & 3.2351 & 1.05042 \\
\hline 13. Contributes in giving more information about the products & .91168 & \\
\hline Grand Mean & $\mathbf{3 . 1 8 6 6}$ & $\mathbf{. 4 5 9 1 6}$ \\
\hline \hline
\end{tabular}


TABLE 3 . Means and standard deviations for sample's responses towards customers' image

\begin{tabular}{lll}
\hline \hline Image & $\mathbf{x}$ & S.D \\
\hline 14. In my opinion, my mobile brand is having a good image in the minds of consumers. & 3.0495 & 1.09478 \\
15. I desire to continue using my mobile brand that uses social media properly. & 3.2426 & 1.07559 \\
16. I trust in using a mobile brand that uses social media properly. & 3.4010 & .94651 \\
17. I know that my mobile brand uses social media successfully. & 3.1287 & 1.11976 \\
18. I believe that my mobile brand copes with sophisticated methods in the area of social media. & 3.2550 & 1.08078 \\
19. I feel that my mobile brand uses social media effectively. & 3.3936 & .95093 \\
\hline \hline
\end{tabular}

\section{Customers' Image}

It was found that there are positive attitudes towards questions mentioned in the table (3) because their means are above the mean of the scale (3).

\section{Hypotheses Testing}

H01: There is no impact of social media on the customers' image for mobiles.

H02: There is no statistical difference in the impact of social media on the customers' image for mobiles due to gender.

H03: There is no statistical difference in the impact of social media on the customers' image for mobiles due to age.

H04: There is no statistical difference in the impact of social media on the customers' image for mobiles due to income.

TABLE 4. Model summary, one-way-ANOVA and coefficients results

\begin{tabular}{lllll}
\hline \hline & \multicolumn{5}{c}{ Model Summary } \\
\hline Model & $\mathbf{R}$ & R-Square & Adjusted R-Square & Std. Error of the Estimate \\
\hline 1 & .521 & .271 & .269 & .59501 \\
\hline Model & Sum of Squares & Df & MNOVA & Sig. \\
\hline Regression & 52.918 & 1 & 52.918 & .000 \\
1 & Residual & 142.322 & 402 & 149.470 \\
& Total & 195.240 & 403 & .354 \\
& & & Coefficients & \\
\hline Model & Unstandardized Coefficients & $\mathbf{t}$ & Sig. \\
\hline \multicolumn{7}{c}{} & Std. Error & & .000 \\
\hline Social media & .789 & .208 & 3.514 & .000 \\
\hline \hline
\end{tabular}

Simple Regression is used to test above hypothesis; it is found that a calculated value of $(F)$ is significant at (0.01) level. This means that null is rejected, which means that there is an impact of social media on the customers' image for mobiles with moderate Pearson correlation of 0.521 .

2-Way ANOVA is used to test above hypothesis and it is found that a calculated value of (F) is not significant at level of (0.05). This means that null is accepted, which means that there is no statistical difference in the impact of social media on the customers' image for mobiles due to age. 
TABLE 5. Tests of between-subjects effects

\begin{tabular}{llllll}
\hline \hline Source & Type III Sum of Squares & df & Mean Square & F & Sig. \\
\hline Corrected model & 78.875 & 50 & 1.577 & 4.785 & .000 \\
Intercept & 1640.007 & 1 & 1640.007 & 4975.040 & .000 \\
Social media & 60.436 & 30 & 2.015 & 6.111 & .000 \\
Gender & .327 & 1 & .327 & .991 & .320 \\
Social media* & 10.004 & 19 & .527 & 1.597 & .054 \\
Gender & & & & & \\
Error & 116.365 & 353 & .330 & & \\
Total & 4449.500 & 404 & & \\
Corrected Total & 195.240 & 403 & & & \\
\hline \hline
\end{tabular}

R-Squared = .404 (Adjusted R-Squared $=.320$ )

TABLE 6. Tests of between-subjects effects

\begin{tabular}{llllll}
\hline \hline Source & Type III Sum of Squares & df & Mean Square & F & Sig. \\
\hline Corrected Model & 83.236 & 62 & 1.343 & 4.087 & .000 \\
Intercept & 664.145 & 1 & 664.145 & 2022.010 & .000 \\
Social media & 59.574 & 30 & 1.986 & 6.046 & .000 \\
Age & 1.912 & 4.478 & 1.456 & .215 & \\
Social media* & & & & & \\
Age & 13.587 & 28 & .485 & 1.477 & .060 \\
Error & 112.004 & 341 & .328 & & \\
Total & 4449.500 & 404 & & & \\
Corrected Total & 195.240 & 403 & & & \\
\hline \hline
\end{tabular}

R-Squared $=.426$ (Adjusted R-Squared $=.322$ )

TABLE 7. Tests of between-subjects effects

\begin{tabular}{llllll}
\hline \hline Source & Type III Sum of Squares & df & Mean Square & F & Sig. \\
\hline Corrected Model & 89.668 & 82 & 1.094 & 3.325 & .000 \\
Intercept & 1407.263 & 1 & 1407.263 & 4278.876 & .000 \\
Social media & 55.892 & 30 & 1.863 & 5.665 & .000 \\
Income & 1.172 & 3 & .391 & 1.188 & .314 \\
Social media* & 20.559 & 49 & .420 & 1.276 & .114 \\
Income & & & & & \\
Error & 105.572 & 321 & .329 & & \\
Total & 4449.500 & 404 & & \\
Corrected Total & 195.240 & 403 & & \\
\hline \hline
\end{tabular}

R-Squared $=.459$ (Adjusted R-Squared $=.321$ )

2-Way ANOVA is used to test above hypothesis and it is found that a calculated value of $(F)$ is not significant at level of (0.05). This means that null is accepted, which means that there is no statistical difference in the impact of social media on the customers' image for mobiles due to age.

2-Way ANOVA is used to test above hypothesis and it is found that a calculated value of $(F)$ is not significant at the level of (0.05). This means that the null is accepted, which means that there is no statistical difference in the impact of social media on the customers' image for mobiles due to income. 


\section{RESULTS}

1-There is an impact of social media on the customers' image for mobiles.

2-There is no statistical difference in the impact of social media on the customers' image for mobiles due to gender.

3-There is no statistical difference in the impact of social media on the customers' image for mobiles due to age.

4-There is no statistical difference in the impact of social media on the customers' image for mobiles due to income.

\section{DISCUSSION}

After presenting a review of social media and Image, this study confirms that social media has an impact on customers' image for mobiles. This result conforms to the common observation that social media plays an important role in the marketing field. On the same track, a study was done in 2014 by (Diga and Tom, 2009) on the importance of social media in marketing during the previous year 2014 and indicated that $92 \%$ of companies worldwide approved that social media in their marketing campaigns proved to be important and essential bearing in mind the results of their ROIs-return on investments - this percentage rises from $86 \%$ in the year 2013 and reaching to $93 \%$ in the year 2015 . The continuous rise in the percentage of companies which rely on social media is a clue that it has the ability to make a successful marketing tool which will limit the use of traditional tools with the course of time. However, it is worth to mention that the total companies which used social media in advertising their products and promoting their business reached the percentage of $96 \%$ in 2014 and $97 \%$ in 2015 . In addition to that, what is so spectacular about social media is the location-based applications which enable the companies to highlight their location along with the marketing plans as a form of decreasing time, money and efforts in marketing. According to Bauer et al. (2005) through e-marketer 33 million people used the location-based applications in their marketing campaigns and this number is expected to double within the coming 5 years. It is also found that there is no statistical difference in the impact of social media on the customers' image for mobiles due to gender, age or income. This reflects the fact that personal characteristics do not affect the importance of social media in its impact on customers' image for mobiles. However, this result proves the speeding pace of the wireless changes that are striking the world; the results of a study by (Bauer et al. 2005) proved that there is a statistical difference of the influence of social media based on the personal characteristics, it made sure that the younger the age group is, the more the influence can be while the current study proves the total opposite. This indicates that the difference between ages will be resolved in the course of time when it comes to mobile and social media marketing.

\section{CONCLUSION AND RECOMMENDATIONS}

Based on the findings following conclusion ca be drawn and recommendations are being given:

1) There is a need to focus on the design of social networking sites to facilitate access to the company's web.

2) Social media advertisements should be uploaded quickly in order to attract customer attention towards them.

3) Mobile companies should prove their ability to modernize their social media tools in order to attract new customers.

4) It is important to repeat this study in other fields to increase the benefits gained from this type of study. 
5) Employees in mobile companies should be well trained on how to use social media in a professional way to convince customers to buy new mobiles.

\section{REFERENCES}

Al-Gohary, Hatem. 2010. E-Marketing-A literature review from a small business perspective. International Journal of Business and Social Science 1, no. 1: 214-244.

Bauer, Hans H., Stuart J. Barnes, Tina Reichardt, and Marcus M. Neumann. 2005. Driving consumer acceptance of mobile marketing: A theoretical framework and empirical study. Journal of Electronic Commerce Research 6, no. 3: 181-192.

Bouchet, Dominique. 2004. What is "Corporate image" and "Corporate identity"-And why do people talk so much about it? Department of Marketing, University of Southern Denmark, Odense, Denmark. URL: goo.gl/EXvUhS (accessed June $30,2015)$.

Cornelissen, Josep. 2000. Corporate image: An audience centered model. Corporate Communications: An International Journal 5, no. 2: 119-125. DOI: 10.1108/13563280010372540 .

Diga, Marichris, and Tom, Kelleher. 2009. Social media use, perceptions of decision-making power, and public relations roles. Public Relations Review 35, no. 4: 440-442. D0I: 10.1016/j.pubrev.2009.07.003 .

Furrer, Olivier and Devanathan Sudharshan. 2001. Internet marketing research: Opportunities and problems. Qualitative Market Research: An International Journal 4, no. 3: 123-129. DOI: 10.1108/13522750110393026.

Kaplan, Andreas M., and Michael Haenlein. 2010. Users of the world, unite! The challenges and opportunities of social media. Business Horizons 53, no. 1: 59-68. D0I: 10.1016/j.bushor.2009.09.003 .

Kehinde, Oyesomi, Ahmadu Frederick and Solarin Adeniyi. 2015. Perceived influence of customers' image of an organization patronage: A focus on Ecobank. Global Journal of Applied, Management and Social Sciences (GOJAMSS) 8, 94103.

Kennedy, Sherril H. 1977. Nurturing corporate image. European Journal of Marketing 11, no. 3: 120-164. DOI: 10.1108/EUM0000000005007.

Kincaid, Susan ed. 2004. Technology in human services: Using technology to improve quality of life. Council for Standards in Human Service Education, Chicago: IL. goo.gl/QohgfC (accessed June 30, 2015).

Kotler, Philip T., and Kevin Lane K. 2006. Marketing management. New Jersey, NJ: Prentice Hall.

Nguyen, Nha, and Gaston Leblanc. 2001. Corporate image and corporate reputation in customers' retention decisions in services. Journal of Retailing and Consumer Services 8, no. 4: 227-236. DOI: 10.1016/S0969-6989(00)00029-1.

Nguyen, Nha. 2006. The collective impact of service workers and service scape on the corporate image formation. Hospitality Management 25, 2: 227-244. DOI: 10.1016/j.ijhm.2005.06.001.

Owen, Robert, and Humphrey Patricia. 2009. The structure of online marketing communication channels. Journal of Management and Marketing Research 2, 1-10.

Russell, E. 2007. The use of face book functions and the effect it has on other methods of communication. Unpublished Master dissertation, The University of Sheffield, Sheffield, UK.

Schiffman, Leon G., and Kanuk Leslie L. 1997. Consumer behavior. New Jersey, NJ: Prentice Hall.

Shankar, Venkatesh and Sridhar Balasubramanian. 2009. Mobile marketing: A synthesis and prognosis. Journal of Interactive Marketing 23, 2: 118-129. DOI: 10.1016/j.intmar.2009.02.002 .

Thiebaud, Jane. 2010. Effects of technology on people: Living F2F conversation and social interaction. Paper presented at the 11th Annual Convention, University of Maine, Orono, Maine, June 10-13.

Vitak, Jessica, Paul Zube, Andrew Smock, Caleb T. Carr, Nicole Ellison, and Cliff Lampe. 2011. 'It's Complicated: Facebook users' political participation in the 2008 election. Cyberpsychology, Behavior, and Social Networking 14, no. 3: $107-\quad$ 114. DOI: $10.1089 /$ cyber.2009.0226. 